\title{
CENTERPARTIETS VÄLJARSTÖD EFTER GUDSTJÄNSTBESÖK 1988-2018
}

\author{
Magnus Hagevi, Institution för statsvetenskap, Linnéuniversitet \\ E-post I magnus.hagevi@lnu.se
}

\section{Inledning}

I en omfattande komparativ studie från slutet av 1960-talet konstaterade Richard Rose och Derek Urwin, till skillnad från allmänt vedertagna antaganden i tidigare forskning, att "[r]eligion, not class, is the main social base of parties in the Western world today." (Rose och Urwin 1969: 12). Därmed skulle religion tendera att vara den viktigaste sociala skiljelinjen i politiken, det vill säga det som identifierar olika samhällsgrupper med motstridiga politiska intressen (Lipset och Rokkan 1967). Utifrån teorier om gruppsocialisation och kognition har framgått att individens religiositet kan relateras till politiska åsikter (Hagevi 2009). En sådan koppling kan röra såväl affektion som kognition. Speciellt religiöst engagerade människor kan använda religion för att orientera sig i politiken och leda dem till vilket parti de ska välja (Hagevi 2018).

Ungefär samtidigt som Rose konstaterade religionens betydelse för röstning i Västvärlden slutade det svenska valforskningsprogrammet att undersöka religionsröstning (Holmberg och Gilljam 1987: 17; jfr Särlvik 1970; Petersson 1977). När dessa undersökningar ett par decennier senare åter studerade den religiösa faktorn vid röstning konstaterade Mikael Gilljam att klass var den starkaste socioekonomiska förklaringen till röstning i Sverige, fast "[ä]nnu 1985 framstår dock den religiösa faktorn som en icke oviktig förklaring till varför svenska väljare röstar som de gör." 
(Holmberg och Gilljam 1987: 210). I Sverige, precis som i andra europeiska länder, tenderade religiöst engagerade väljare att i större utsträckning rösta på borgerliga partier (Holmberg och Gilljam 1987), ett samband som senare studier bekräftat (Hagevi 2009). Gilljam noterade också att sambandet mellan religiöst engagemang och partival hade minskat från slutet av 1960-talet till mitten av 1980-talet (Holmberg och Gilljam 1987). Även senare studier visar att sambandet mellan väljarnas religiösa engagemang och partival minskat (Hagevi 2018). Religionens minskade politiska betydelse är i linje med dealignment - att den politiska betydelsen av socioekonomiska skiljelinjer minskar och att socioekonomiska faktorer som klass och religion förklarar allt mindre av väljarnas partival (Dalton $\mathrm{m}$ fl 1984). I den omfattande forskningen om väljar-dealignment visar de flesta resultat att de sociala skiljelinjer, som en gång varit betydelsefulla, har minskat i betydelse (Dalton 2013; Oscarsson och Holmberg 2013). Detta kan sättas i samband med sekularisering, det vill säga att religion betyder allt mindre för allt fler människor och inom allt fler samhällsområden (Hagevi 2009). En sådan förändring implicerar bland annat att religiösa väljare $\mathrm{i}$ allt mindre utsträckning röstat på partier som traditionellt företräder dem. Vid sidan av denna förändring har andelen religiöst engagerade väljare minskat (Hagevi 2018), vilket minskar religiösa väljares inflytande över valresultaten.

Det finns forskare som menar att dealignment utmed religiösa skiljelinjer är mindre omfattande (Inglehart 1977: 217-225). För det första antas att familjesocialisationen är starkare för religion än för andra sociala skiljelinjer: föräldrarna tros vara mer måna om att föra över värden och åsikter knutna till religion jämfört med till exempel klass. För det andra innebär sekularisering ett ifrågasättande av religiösa värden, vilket kan aktivera religiösa väljare politiskt och stärka sambandet mellan religiöst engagemang och partival.

På 1910-talet etablerades Bondeförbundet i Riksdagen, ett parti som 1957-1958 bytte namn till Centerpartiet (Möller 2019). Traditionellt har Centerpartiet varit starkt förknippat med Svenska kyrkan, speciellt på landsbygden (Lipset och Rokkan 1967). Under 1970-talet hade partiet en mycket stark position bland gudstjänstbesökarna i Svenska kyrkan och vann också väljare bland frikyrkofolket (Hagevi 2011: 259). Under 1980-talet försvagades dock Centerpartiets position bland de kyrkligt aktiva. Samtidigt slutade partiet hänvisa till kristendom som en grund för sin politik: sista gången Centerpartiet i sitt valmanifest menade att partiets "människosyn har sin grund i den kristna livsåskådningen" var inför riksdagsvalet 1979 (Centerpartiet 1979). Partiet var också länge tveksamt till att förändra Svenska kyrkans roll som statskyrka. Anledningen till att partiet ändå ställde sig bakom de förändrade relationerna mellan staten och Svenska kyrkan vid millennieskiftet var att Centerpartiet inte betraktade förslaget som en skilsmässa mellan kyrka och stat: det rörde sig endast om förändrade relationer (Gunnervik 2002). Bland riksdagspartierna ställer Centerpartiet alltjämt upp i valen inom Svenska kyrkan. Detta gör det extra intressant att söka ett svar på frågan: Vilket samband finns mellan väljarnas gudstjänstbesök och stöd för Centerpartiet?

I det följande presenterar först studiens data, variabler och statistiska mått. Sedan beskrivs sambandet mellan gudstjänstbesök och Centerpartiet. Till sist presenteras studiens huvudslutsatser. 


\section{Data och variabler}

Avsikten är att studera sambandet mellan gudstjänstbesök och stödet för Centerpartiet bland svenska väljare. För att kunna uttala sig om detta behövs data. I dessa data indikeras religiöst engagemang med individens vana att besöka gudstjänster. Det finns givetvis många andra sätt att undersöka religiöst engagemang (Leege och Kellstedt 1993). Gudstjänstbesök är inriktat på beteende, medan det finns religiöst engagemang som är mer psykologiskt. Fördelen att analysera gudstjänstbesök är att detta kan knytas till teoretiska antaganden om socialisation där affektion respektive kognition är viktiga element. Gudstjänstbesök är en religionsutövning som till stor del är relaterad till kristendom. Personer som minst en gång i månaden besöker gudstjänst identifierar sig 88 procent som kristna, medan 5 procent identifierar som muslimer ( $\mathrm{n}=104)$ (Hagevi 2018).

Studiens data är vetenskapliga frågeundersökningar av svenska väljare och svenska befolkningen. För att undersöka tre decenniers väljarbeteende är det två sorters sådana data som används: SVTvalu och SOM-institutets undersökningar. Båda analyseras utan viktningar i urvalet. För det första studeras väljarnas gudstjänstbesök och röstning genom SVT-valu 1991-2018. SVT-valu är en vallokalsundersökning som genomförs av Sveriges television i samarbete med Göteborgs universitet och Kungliga tekniska högskolan (Oscarsson m fl 2018). Vid ett urval av röstställen ombeds väljarna att fylla i enkäter efter att de lämnar vallokalen.

Enkäten behandlar bland annat hur svarspersonera röstat och hur ofta de besöker gudstjänst. Frågan om gudstjänstbesök lyder: "Hur ofta brukar Du gå till gudstjänst eller på möte i någon kyrka/religiöst samfund?" med svarsmöjligheterna "Minst en gång i månaden", "Några gånger om året", "Mera sällan" och "Aldrig". Svaren i tre kategorier: aldrig ("Aldrig"), sällan ("Några gånger om året" och "Mera sällan") och regelbundet ("Minst en gång i månaden"). Ju oftare väljaren besöker gudstjänst, desto större antas individens religiösa engagemang vara. Om väljarna röstar på Centerpartiet undersöks med frågan "Vilket parti röstade på i dag i riksdagsvalet?" Genom att vid två tillfällen (1991 och 1998) använda frågan om hur väljaren röstade i föregående riksdagsval är det möjligt att förlänga tidserien till 1988 samt erhålla data om gudstjänstbesök och partival 1994 (då väljarnas gudstjänstbesök inte undersöktes i SVT-valu). Frågan om hur väljarna röstade i föregående riksdagsval lyder: Vilket parti röstade Du på i förra riksdagsvalet [1988 eller 1994]? Procentbasen beräknas på alla väljare som uppger att de röstade på ett parti i riksdagsvalet.

Beroende på när enkäten genomfördes varierar det totala antalet svarande. Vid valet 1991 besvarade drygt 2700 personer enkäten, i valen 1994-2002 var antalet svarande ungefär 70009000 personer och 2006-2018 var antalet svaranden ungefär 11000-13000 personer. Det varierande antalet svarande på enkäten är en av två centrala orsaker till att antalet svarande som besöker gudstjänst regelbundet, sällan och aldrig varierar mellan olika undersökningstillfällen. Den andra orsaken är sekularisering som främst innebär att antalet som kategoriserats som att de sällan besöker gudstjänst över tid minskar i antal och att personer som svarat att del aldrig besöker gudstjänst ökar i antal (Hagevi 2018). Utifrån 1991 års SVT-valu var antalet svarande för skattningarna 1988 och 1991 bland de som besöker gudstjänst regelbundet 179-188 personer, sällan 1359-1435 personer och bland aldrig 788-899 personer. I skattningarna av partival mellan 1994 och 2002 var antalet svarande bland de som besöker gudstjänst regelbundet 596-633 
personer, sällan 4566-4864 personer och aldrig 2501-3198 personer. Mellan 2006-2018 var antalet svarande bland de som besöker gudstjänst regelbundet 719-854 personer, sällan 47195904 personer och aldrig 5008-5948 personer.

För det andra studeras gudstjänstbesök och partisympati genom de frågeundersökningar som genomförts av SOM-institutet vid Göteborgs universitet mellan 1988-2018 (SOM-institutet 2019). Dessa frågeundersökningar genomförs i form av postenkäter riktade till representativa urval av svenska befolkningen mellan 16-75/80/85 år (den övre åldersgränsen har succesivt höjts i undersökningarna). I SOM-undersökningar studeras gudstjänstbesök i ett frågebatteri som inleds med följande fråga: "Hur ofta har Du under de senaste 12 månaderna gjort följande saker?" Därefter nämns bland annat "Besökt gudstjänst eller religiöst möte". Svarsalternativen är "Ingen gång", "Någon gång under de senaste 12 månaderna", "Någon gång i halvåret", "Någon gång i kvartalet", "Någon gång i månaden", "Någon gång i veckan" samt "Flera gånger i veckan". Dessa uppgifter analyseras genom att dela in svaren i tre kategorier: aldrig ("Ingen gång"), sällan (från "Någon gång under de senaste 12 månaderna" till "Någon gång i kvartalet") och regelbundet (från "Någon gång i månaden" till "Flera gånger i veckan").

I SOM-undersökningarna registreras partisympati med Centerpartiet med frågan "Vilket parti tycker Du bäst om idag?" Procentbasen beräknas på alla väljare som uppgav partisympati. Notera att SOM-institutet genomför sina undersökningar varje år, inte bara vid riksdagsval. Därför analyseras inte svarspersonernas röstning utan deras partisympatier, något som väljarna kan redovisa även när det inte är val.

Beroende på vilket år undersökningen genomförs har SOM-institutet riktat frågan om gudstjänstbesök till olika stora urval. Åren 1988-1997, 2002-2004, 2014-2016 och 2018 varierade antalet svarande mellan ungefär 1300 och 1700 personer och åren 1998-2001, 20052013 och 2017 varierade antalet svarande mellan ungefär 2750 och 3200 personer. Återigen är det varierande antalet svarande på SOM-undersökningar en av två centrala orsaker till att antalet svarande som besöker gudstjänst regelbundet, sällan och aldrig varierar mellan olika undersökningstillfällen. Också nu är den andra orsaken den sekularisering som främst innebär att antalet som kategoriserats som att de sällan besöker gudstjänst över tid minskar i antal och att personer som svarat att del aldrig besöker gudstjänst ökar i antal (Hagevi 2018). Under åren med ett mindre urval är antalet svarande bland de som besöker gudstjänst regelbundet 110-201 personer, sällan 338-712 personer och aldrig 573-1137 personer. Under åren med ett större urval är antalet svarande bland de som besöker gudstjänst regelbundet 197-321 personer, sällan 6721191 personer och aldrig 1641-2152 personer.

I SOM-institutets undersökningar kan det vara ett ganska litet antal svarande som uppger att de besöker gudstjänst regelbundet. Därför är den statistiska osäkerheten större i skattningar av denna grupps partisympatier. Något som ökar säkerheten i SOM-undersökningarnas skattningar av partisympatier bland regelbundna gudstjänstbesökare är möjligheten till jämförelse över tid. Det rör sig då om betydligt fler svarspersoner än ett enstaka år. I den mån som en skattning inte kraftigt avviker från de intilliggande åren ökar därför trovärdigheten i skattningen. Plötsliga förändringar ett år som inte upprepas återkommande år har istället lägre trovärdighet. Möjligheten att under valår jämföra partisympatierna bland regelbundna gudstjänstbesökare i SOM-undersökningarna 
med motsvarande kategori i SVT-valu - som har betydligt större antal svarande - kan också validera resultaten från SOM-undersökningarna.

För att ytterligare validera SOM-institutets data jämförs resultat från 2010-2018 med motsvarande data som samlats in av Surveyinstitutet vid Linnéuniversitetet (Hagevi 2020). Behovet av att validera data rör speciellt gruppen regelbundna gudstjänstbesökare då antalet svarspersoner $\mathrm{i}$ denna grupp är få. Surveyinstitutet genomför frågeundersökningar vartannat år i form av postenkäter riktade till representativa urval av svenska befolkningen mellan 16/18-85 år (den yngre åldersgränsen höjdes 2014). I Surveyinstitutets undersökningar studeras gudstjänstbesök i ett frågebatteri som inleds med följande fråga: "Hur ofta har du under de senaste 12 månaderna gjort följande?" varpå mellan 2010-2016 "Besökt religiöst möte (t ex gudstjänst eller bön)" och 2018 "Besökt gudstjänst" nämns. Svarsalternativen är "Ingen gång", "Någon gång de senaste 12 månaderna", "Någon gång i halvåret", "Någon gång i kvartalet", "Någon gång i månaden", "Någon gång i veckan", "Flera gånger i veckan" och "Varje dag". Dessa uppgifter analyseras genom att dela in svaren i tre kategorier: aldrig ("Ingen gång"), sällan (från "Någon gång under de senaste 12 månaderna" till "Någon gång i kvartalet") och regelbundet (från "Någon gång i månaden" till "Varje dag").

Surveyinstitutet undersöker centerpartistisk partisympati genom frågan "Vilket parti tycker du bäst om idag?" Procentbasen beräknas på alla väljare som uppgav partisympati. Notera att Surveyinstitutet genomför sina undersökningar vartannat år, inte bara vid riksdagsval. Därför analyseras inte svarspersonernas röstning utan deras partisympatier, något som väljarna kan redovisa även när det inte är val.

I Surveyinstitutets undersökningar varierar antalet svarande mellan 1170 och 1490 personer. Under åren är antalet svarande bland de som besöker gudstjänst regelbundet 80-129 personer, sällan 407-515 personer och aldrig 655-846 personer.

\section{Stödet för Centerpartiet efter gudstjänstbesök}

I figur 1 beskrivs andelen väljare som röstat på Centerpartiet i riksdagsvalen efter gudstjänstbesök. I figur 2 rapporteras andelen i svenska befolkningen som sympatiserar med Centerpartiet efter gudstjänstbesök. Partiets stöd bland regelbundna gudstjänstbesökare markeras med heldragen svart linje, bland de som besöker gudstjänst sällan markeras med streckad linje och de som aldrig besöker gudstjänst markeras med prickad linje. 
Figur 1: Röstning på Centerpartiet, efter gudstjänstbesök, 1988-2018 (procent).

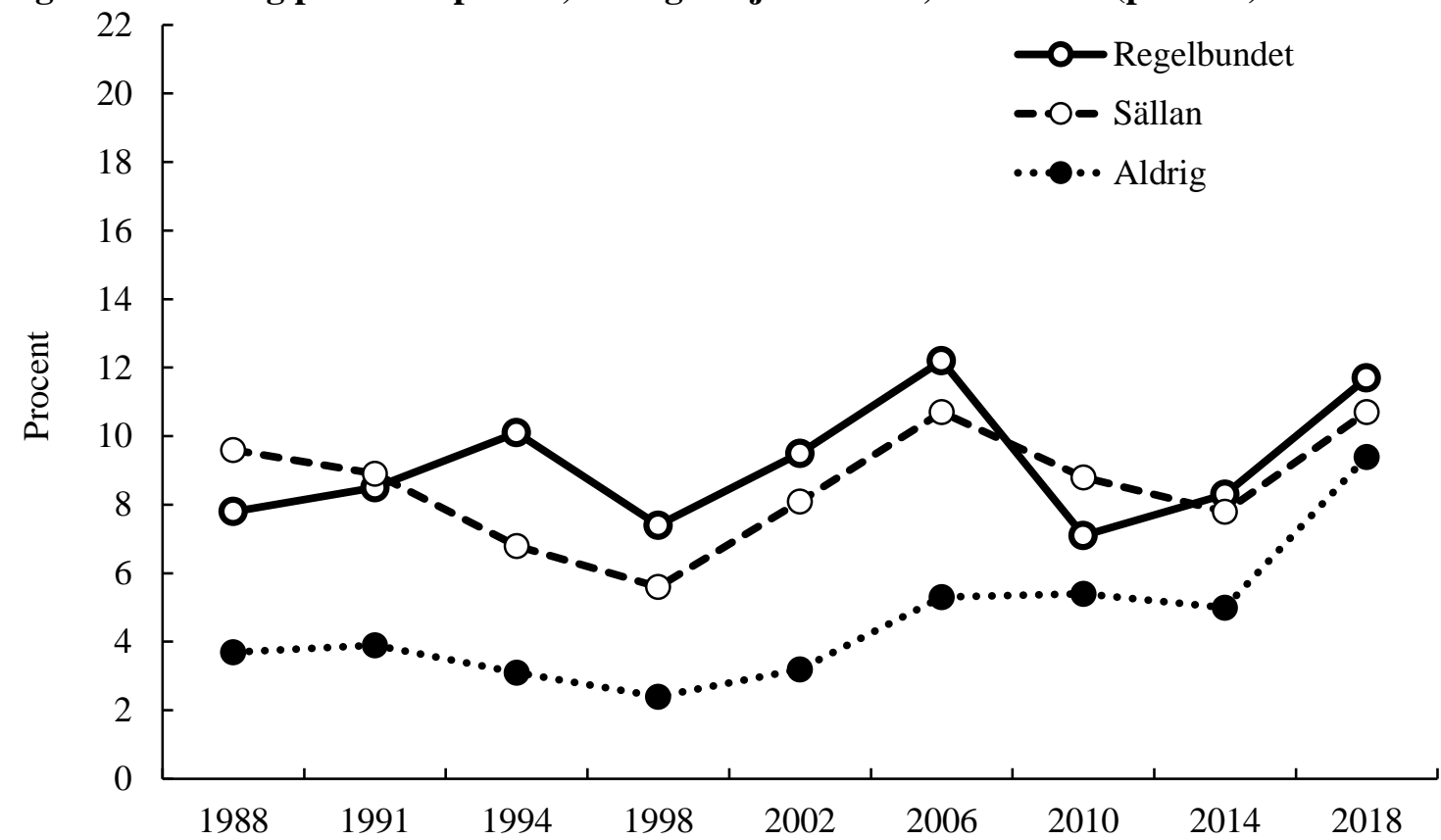

Kommentar: Data från SVT-valu. Frågan om röstning löd: "Vilket parti röstade på i dag i riksdagsvalet?", undantaget 1988 och 1994 då minnesuppgifter från 1991 respektive 1998 används: "Vilket parti röstade Du på i förra riksdagsvalet [1988/1994]?" Frågan om gudstjänstbesök löd: "Hur ofta brukar Du gå till gudstjänst eller på möte i någon kyrka/religiöst samfund?" Det var möjligt att svara "Minst en gång i månaden" (regelbundet), "Några gånger om året", "Mera sällan" (båda kategoriseras som sällan) och "Aldrig" (aldrig).

Figur 2: Partisympati för Centerpartiet, efter gudstjänstbesök, 1988-2018 (procent).

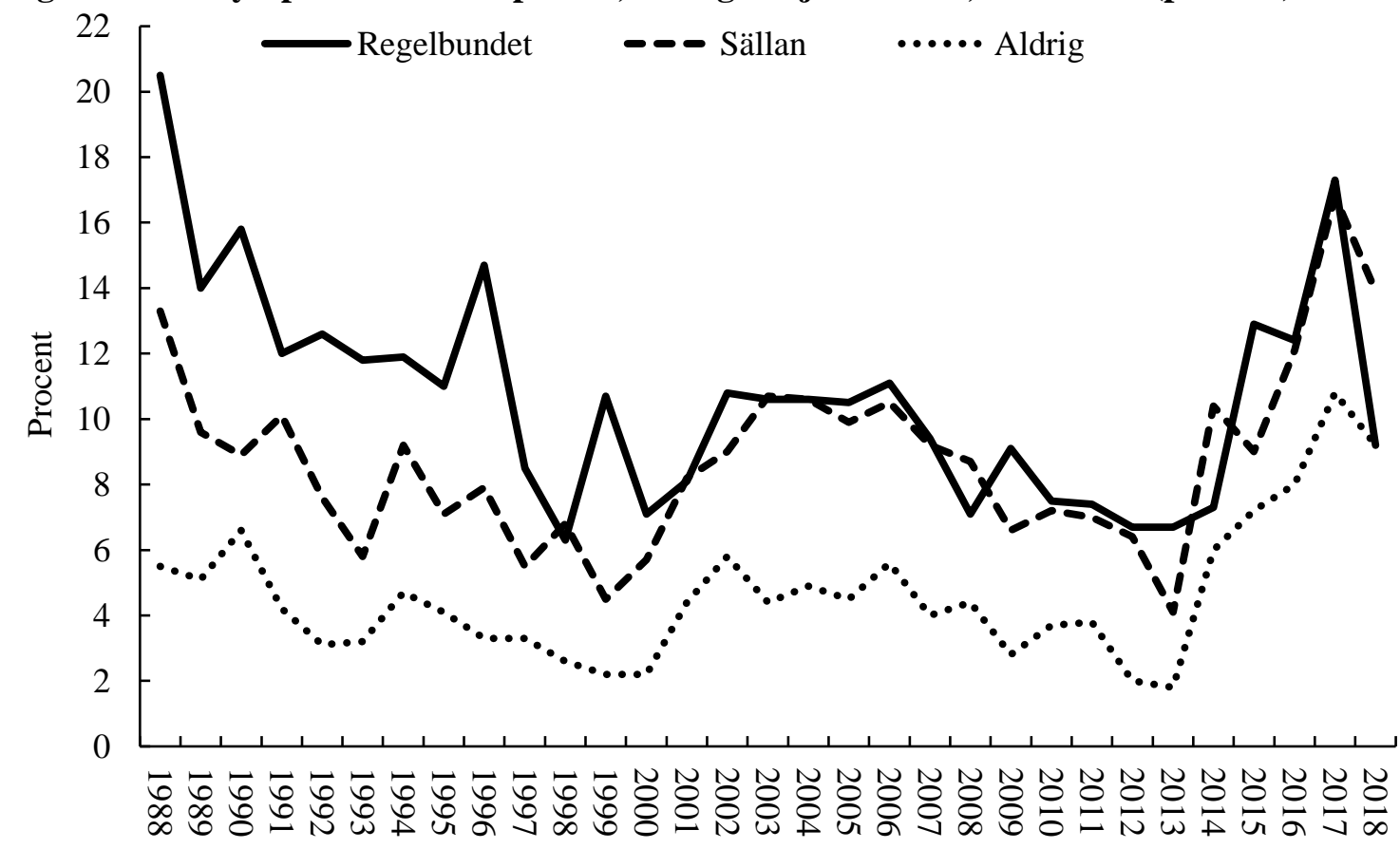


Kommentar: Data från SOM-institutet. Frågan om partisympati löd: "Vilket parti tycker Du bäst om idag?" Frågan om gudstjänstbesök löd: "Hur ofta har du under de senaste 12 månaderna gjort följande?", varpå bland annat "Besökt gudstjänst eller religiöst möte" nämndes. Det var möjligt att svara "Ingen gång" (kategoriserad som "aldrig"), " Någon gång under de senaste 12 månaderna", "Någon gång $i$ halvåret", "Någon gång i kvartalet" (dessa tre svar kategoriserade som "sällan"), "Någon gång i månaden", "Någon gång i veckan" och "Flera gånger i veckan" (dessa tre svar kategoriserade som "regelbundet").

Under nästan hela undersökningsperioden från 1988 och framåt är Centerpartiets stöd bland väljare som aldrig besöker gudstjänst något lägre än bland gudstjänstbesökande väljare. Bland de som sällan eller regelbundet besöker gudstjänst är det inte stor skillnad i stödet för Centerpartiet, men ofta är stödet något starkare bland regelbundna gudstjänstbesökare (speciellt före millennieskiftet enligt SOM-undersökningarna i figur 2). Enligt SVT-valu i figur 1 går Centerpartiet fram bland väljare som aldrig besöker gudstjänst vid riksdagsvalet 2018 utan att för den skull tappa stöd bland de som besöker gudstjänst. Vid en jämförelse av SOM-institutets uppgifter från valåren 2014 och 2018 i figur 2 noteras ungefär samma sak. Eftersom SOMinstitutet undersöker partisympatierna under åren mellan valen är det ocskå möjligt att notera att Centerpartiet får ett kraftigt ökat stöd bland gudstjänstbesökande väljare 2015-2017 (både bland de som besöker gudstjänst regelbundet och sällan). En stor del av detta stöd förloras dock under valåret, speciellt bland regelbundna gudstjänstbesökare.

Bland regelbundna gudstjänstbesökare är antalet svarande relativt få i SOM-undersökningarna. Till dessa skattningar finns därför en ökad osäkerhet jämfört med motsvarande kategori i SVTvalu. Under den senare undersökningsperioden - då centeropinionen rör sig mycket bland väljare med olika gudstjänstvanor - är det dock möjligt att hämta uppgifter från Surveyinstitutet frågeundersökningar. Åren 2010-2018 undersökte också Surveyinstitutet väljarnas gudstjänstbesök och partisympatier. Likt SOM-undersökningarna har även Surveyinstitutets undersökningar relativt få svarande som besöker gudstjänst regelbundet. Men om Surveyinstitutets undersökningar visar motsvarande resultat - att stödet för Centerpartiet ökar bland de som aldrig besöker gudstjänst 2018 och att stödet för partiet var extra starkt bland gudstjänstbesökarna åren före riksdagsvalet 2018 - stärks slutsatsen att denna förändring ägt rum. I figur 3 redovisas stödet för Socialdemokraterna efter gudstjänstbesök 2010-2108. Partiets stöd bland regelbundna gudstjänstbesökare markeras med heldragen svart linje, bland de som besöker gudstjänst sällan markeras med streckad linje och de som aldrig besöker gudstjänst markeras med prickad linje. 
Figur 3: Partisympati för Centerpartiet, efter gudstjänstbesök, 1988-2018 (procent).

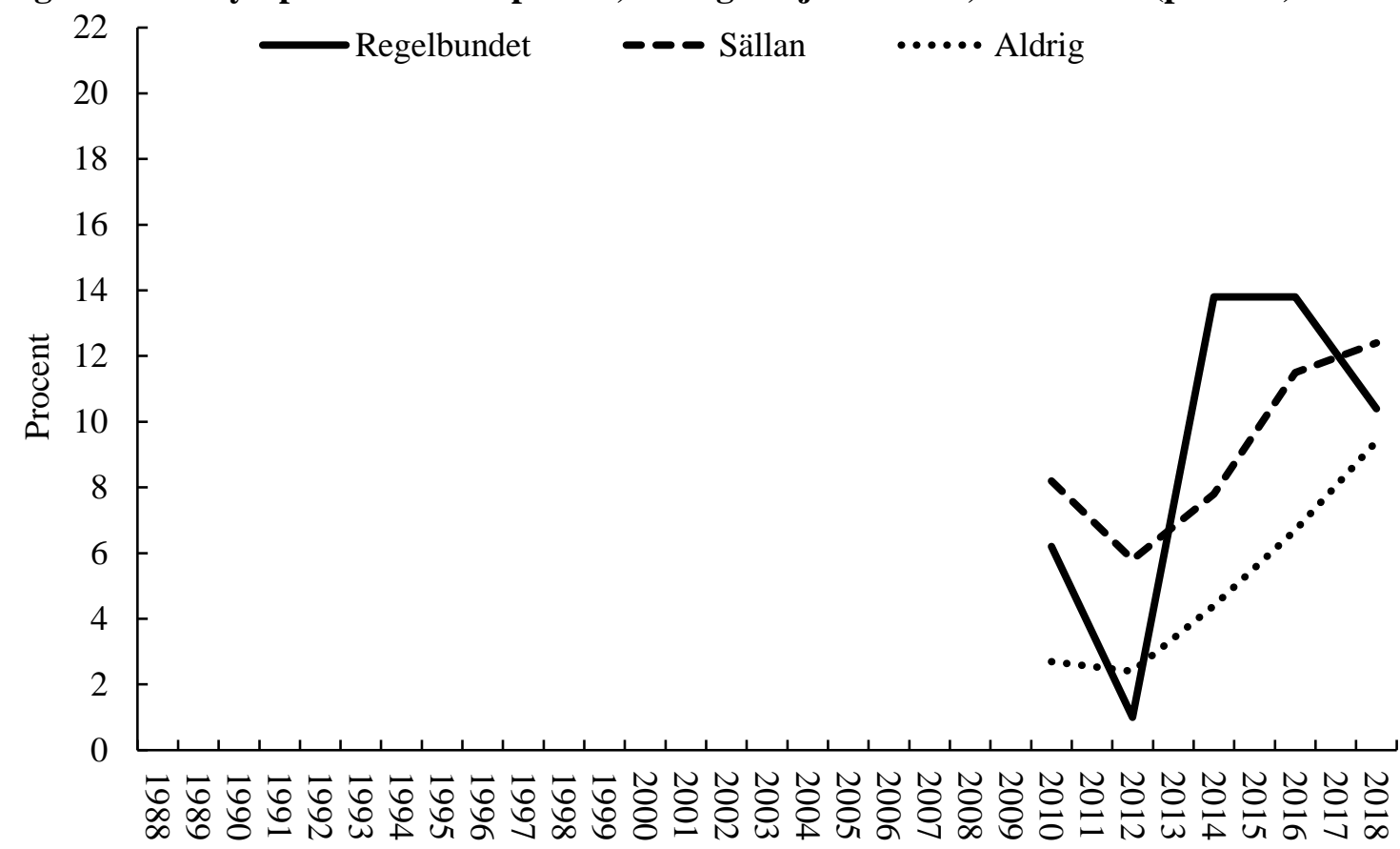

Kommentar: Data från Surveyinstitutet. Frågan om partisympati löd: "Vilket parti tycker Du bäst om idag?" Frågan om gudstjänstbesök löd: "Hur ofta har du under de senaste 12 månaderna gjort följande?", varpå bland annat "Besökt religiöst möte (gudstjänst eller bön)" alternativt " Besökt gudstjänst" nämndes. Det var möjligt att svara "Ingen gång" (kategoriserad som "aldrig"), " Någon gång under de senaste 12 månaderna", "Någon gång i halvåret", "Någon gång i kvartalet" (dessa tre svar kategoriserade som "sällan"), "Någon gång i månaden", "Någon gång i veckan", "Flera gånger i veckan" och "Varje dag" (dessa fyra svar kategoriserade som "regelbundet").

Också i Surveyinstitutets undersökningar tenderar gudstjänstbesökarna (undantaget de regelbundna gudstjänstbesökarna 2012) ge ett starkare stöd till Centerpartiet än vad som är fallet för väljare som aldrig besöker gudstjänst (eftersom C-stödet bland regelbundna gudstjänstbesökare 2012 är en enstaka avvikelse där antalet svarande är få tillmäts inte detta resultat någon stor betydelse). Men likt SVT-valu och SOM-institutet ökar stödet för Centerpartiet bland väljare som aldrig besöker gudstjänst 2018. I detta visar således de tre undersökningarna samma resultat, varför mycket tyder på att Centerpartiet gick fram bland de mest sekulära väljargrupperna vid riksdagsvalet 2018. Vid en jämförelse av valåren 2014 och 2018 gick Centerpartiet förhållandevis bra också bland gudstjänstbesökare. Någon omfattande tillbakagång från en opinionstopp bland gudstjänstbesökarna är inte lika synlig i Surveyinstitutets data i figur 3 som i SOM-institutets uppgifter i figur 2, med ett möjligt undantag för regelbundna gudstjänstbesökare (vilket är ett osäkert resultat då antalet svarande är få).

\section{Slutsatser}

Centerpartiet har länge haft en starkare position bland gudstjänstbesökare - såväl de som gör sådana besök regelbundet som mera sällan - än bland väljare som aldrig besöker gudstjänst. Det 
finns ingenting i denna studie som visar på att detta förhållande kommer har ändrats annat än att partiet i senaste valet också ökade sitt stöd bland väljare som aldrig besöker gudstjänst. Efter Kristdemokraterna brukar Centerpartiet vara det parti som vinner mest väljare på religionsröstning. Under valåret 2018 ökade partiets stöd bland de mest sekulära väljarna. Därför minskade skillnaderna i Centerpartistöd mellan de som regelbundet, sällan eller aldrig besöker gudstjänst. Denna förändring är en av anledningarna till att religionsröstningen minskar bland svenska väljare (Hagevi 2018).

\section{Referenser}

Centerpartiet (1979) Program inför valet den 16 september 1979: Antaget av centerpartiets förtroenderåd den 14 augusti 1979 i Malmö. Göteborg: Svensk nationell datatjänst (internet: https://snd.gu.se/sv/vivill/party/c/v/1979, hämtat 2020-12-18).

Dalton, Russell J. (2013) Citizen Politics: Public Opinion and Political Parties in Advanced Industrial Democracies. Washington, DC: CQ Press.

Dalton, Russell J, Scott C Flanagan och Paul Allen Beck, red (1984) Electoral Change in Advanced Industrial Democracies: Realignment or Dealignment? Princeton: Princeton University Press.

Gunnervik, Sara (2002) Kyrka - stat debatt i hundra år: En analys av hur maktdebatten återspeglades $i$ offentligt tryck. Examensuppsats. Lund: Juridiska fakulteten, Rättshistoria, Lunds Universitet.

Hagevi, Magnus (2009) Politisk opinion och religiositet i Västra Götaland. Lund: Sekel.

Hagevi, Magnus (2011) "Religiositet" s 250-267 i Den svenska väljaren, red Magnus Hagevi. Umeå: Borea.

Hagevi, Magnus (2018) ”Religionsröstning i Sverige 1988-2018." Surveyjournalen, 5 (1): 2-14. Hagevi, Magnus (2020, kommande). ”Survey 2018: Teknisk rapport.” Surveyjournalen, 7 (1). Holmberg, Sören och Mikael Gilljam (1987). Väljare och val i Sverige. Stockholm: Bonniers. Inglehart, Ronald (1977). The Silent Revolution: Changing Values and Political Styles Among Western Publics. Princeton: Princeton University Press.

Leege, David och Lyman Kellstedt, red (1993) Rediscovering the Religious Factor in American Politics. Armonk: M. E. Sharpe.

Lipset, Seymour M. och Stein Rokkan (1967) "Cleavage Structures, Party Systems, and Voter Alignments: An Introduction", s 1-64 i Party Systems and Voter Alignments, red Seymour Lipset och Stein Rokkan. New York: The Free Press. 
Oscarsson, Henrik och Sören Holmberg (2013) Nya svenska väljare. Stockholm: Norstedts juridik.

Oscarsson, Henrik Ekengren, Per Näsman, Eva Landahl och Sören Holmberg (2018) VALU 2018 - SVT:s vallokalsundersökning riksdagsvalet 2018. Stockholm: Sveriges Television AB

Petersson, Olof (1977) Väljarna och valet 1976. Stockholm: Statistiska centralbyrån/Liber.

Rose, Richard och Derek Urwin (1969), "Social Cohesion, Political Parties and Strains in Regimes." Comparative Political Studies, 2 (1): 7-67.

SOM-institutet (2019) Super-Riks-SOM 1986-2018 (v2019.1). Göteborg: SOM-institutet, Göteborgs universitet.

Särlvik, Bo (1970) "Socioeconomic Position, Religious Behavior, and Voting in the Swedish Electorate: An Application of Computerized Classification Techniques." Quality and Quantity, 4 (1): 95-116. 